\title{
DOCE LECCIONES DEL TERREMOTO CHILENO
}

\author{
Sergio Bitar \\ Ex Ministro de Obras Públicas \\ Gobierno de Chile
}

El presente documento corresponde a una exposición del autor en la $39^{\circ}$ conferencia de Latin American Studies Association (LASA) en la cual se reflexiona sobre las enseñanzas que dejó el terremoto que afectó a Chile en febrero del 2010 para perfeccionar la acción del Estado ante desastres futuros, en Chile y América Latina.

Palabras clave: Terremoto; gestión; Chile.

\section{Twelve lessons from the 2010 chilean earthquake}

This document corresponds to a paper presented at the XXIX conference of the Latin American Studies Association (LASA), and offers some lessons resulting from the 2010 earthquake in Chile. The central focus is on improving State action in the face of future disasters, in Chile and Latin America.

Keywords: earthquake; management; Chile. 


\section{INTRODUCCIÓN ${ }^{1}$}

A las 3:30 am del sábado 27 de febrero de 2010, momento en que el terremotomaremoto comenzó a desencadenarse en Chile, me desempeñaba como Ministro de Obras Públicas. Desde ese instante hasta el cambio de gobierno, el 11 de marzo, enfrenté las ominosas consecuencias humanas, materiales y de infraestructura de este doble desastre natural.

He aquí algunas de mis primeras impresiones y conclusiones, que espero sean útiles para perfeccionar nuestra acción ante desastres futuros, en Chile y América Latina. Pero veamos primero la magnitud de ese desastre natural.

\section{CONSIDERACIONES GENERALES}

El mega terremoto, el mayor registrado en los últimos 50 ańos en el planeta -y el quinto mayor de los últimos 1.200 años según el Servicio Geológico de EEUUalcanzó 8,8 grados en escala Richter en la zona de Concepción, segunda ciudad de Chile en población.

Sus efectos fueron masivos: se extendió por más de 300 kilómetros de costa, azotó a cinco ciudades con más de 100.000 habitantes y a otras cuarenta y cinco ciudades de más de 5.000. Cerca de 500 personas perdieron la vida. Más de 50.000 familias quedaron sin techo y 200.000 viviendas sufrieron severos daños. Por otra parte, se perdieron más de 4 mil camas hospitalarias, que representaban alrededor del 50\% de las camas del sistema público. Muchos hospitales quedaron inutilizables, varios cientos de miles de estudiantes perdieron sus escuelas o las hallaron muy dañadas, teniendo que proseguir sus clases en otros establecimientos.

Sin considerar lucro cesante, el costo fiscal estimado de los daños provocados por el terremoto-maremoto alcanza un monto de entre 8 y 10 mil millones de dólares, el equivalente a la inversión pública de un año normal.

1 Texto presentado en la conferencia de Latin American Studies Association (LASA), Toronto, Canadá, octubre 2010. 
A pesar de la enorme intensidad del sismo, la infraestructura resistió bien. A los pocos días, el país se encontraba conectado por aire, mar y tierra, de forma que la ayuda pudo arribar, de una forma u otra, a todos los puntos del país.

El número de edificios colapsados fue limitado. De unos 10.000 que fueron sometidos al impacto telúrico, en solo 1 se lamentaron muertes y 10 resultaron irrecuperables (Sarrazín, 2010). La mayor destrucción ocurrió en los cascos antiguos de ciudades y pueblos, en construcciones de adobe, y en las instalaciones costeras a baja altura, las que fueron devastadas por el maremoto.

No obstante, en desastres naturales como éste el verdadero drama es humano, y es lo primero que debe concentrar la atención y acción inmediata de un gobierno y de la sociedad toda: la emergencia, sobrevivir, comer, sanar y-luego de superado ese trance- iniciar la tarea más compleja: reconstruir vidas, ciudades y pueblos.

Resulta muy difícil evaluar el efecto de un evento de esta magnitud sobre las personas, el desplome de esperanzas, la pérdida de seres queridos, los dolores, traumas y temores. Más aún, si se considera la interminable sucesión de réplicas de intensidad superior a 5 grados en la escala Richter, que mantuvo en vilo y en la angustia a numerosas familias. Indudablemente, las consecuencias humanas, a ratos invisibles y perdurables, son más importantes que los daños materiales.

Cuatro son los grandes problemas que explotan en estas dramáticas circunstancias, y que ponen a prueba la capacidad institucional del Estado: las comunicaciones, que deben ser inmediatas; el orden público, indispensable para actuar ante una emergencia; el financiamiento para ir en auxilio de las víctimas, y el diseño e implementación de los planes de reconstrucción.

\section{DOCE LECCIONES PARA EL FUTURO}

De esta intensa vivencia extraigo algunas lecciones (doce) para mejorar nuestra capacidad de enfrentar futuros desastres naturales

Primera: El violento remezón cortó el sistema de comunicaciones. Éste fue un obstáculo mayor para auxiliar a las víctimas y evaluar los daños con prontitud. La interrupción total de los servicios básicos de comunicaciones -y parcial, en el caso del suministro de electricidad y agua- fue muy crítica en las primeras horas. 
La confianza en las redes de teléfonos fijos y celulares, que dependen de la electricidad y que colapsaron rápidamente, sumada a la falta de un sistema de telefonía satelital, aisló por largas horas a las zonas más dañadas. El consecuente aislamiento e incomunicación se acentuaron producto del desmantelamiento progresivo de los sistemas con tecnología antigua, como la radio.

Esa misma mañana, la presidenta y sus ministros nos desplazamos a las zonas afectadas para constatar directamente la magnitud del daño. Horas después, el suministro de servicios básicos comenzó a restablecerse.

Considerando la situación descrita, me parece necesario disponer de un sistema paralelo de comunicación territorial, independiente de la red comercial y del abastecimiento eléctrico por las redes normales, que conecte al Gobierno, FFAA, policías, servicios de salud, bomberos y otros órganos de protección civil.

De haber existido un sistema de comunicación autónomo, éste habría evitado demoras y permitido una más rápida organización en auxilio de las localidades más azotadas. Disponer de este sistema adicional de cobertura resulta esencial $-y$ significativamente más seguro- para responder ágil y eficazmente ante desastres de tal envergadura.

Segunda: El control del orden público es indispensable para responder con rapidez a la necesidad urgente de atención de salud, alimentación, ropas, combustible; de restablecimiento de los servicios fundamentales, y -en los días siguientesretiro de escombros.

En Concepción, a pocas horas del terremoto, la policía fue desbordada y comenzaron pillajes en el comercio, sumiendo en el temor tanto a la población como a las cuadrillas de trabajadores que debían iniciar la reposición de los servicios básicos.

Una revisión de los sismos que han tenido lugar en Chile y el mundo permite detectar un patrón común: al producirse un vacío de poder se puede generar un cambio abrupto, casi inconsciente, en la conducta individual y social, al punto de que se desaten olas de pillaje y robo entre vecinos y personas decentes. Así ha ocurrido en otros casos de desastres de envergadura, como el reciente terremoto de Nueva Zelandia. 
Lo acontecido en Concepción fue chocante, y muchos individuos devolvieron las especies que habían sustraído luego de ser advertidos, días después, de que sus casas serían registradas por la policía. Algunos declararon haber sido víctimas de un desvarío colectivo, y sentirse arrepentidos de lo hecho.

El gobierno ordenó de inmediato a las Fuerzas Armadas ir en auxilio de las familias. Sin embargo, la orden de tomar el mando total, con toque de queda, se dictó mediante decreto presidencial al día siguiente. Los debates posteriores en el Congreso se concentraron en que tal medida debió haber sido dada el mismo sábado por la tarde, a 12 horas de ocurrido el terremoto-maremoto, y no el Domingo, pasadas 36 horas. No obstante, al asistir a la conferencia de prensa donde se anunció esta medida, el domingo 28 a las 15 hrs., pude constatar que los efectivos de la Armada estaban en plena faena para contener el gran desastre en sus instalaciones navales y del principal astillero de Chile, ASMAR. A consecuencia de ello, el Ejército debió trasladar más personal de otras zonas del país, para cumplir su doble función de auxilio y orden ese domingo.

Aquí hay una lección importante: es imprescindible diseñar un sistema que agilice la delegación a las FFAA del mando administrativo de la zona afectada, por un plazo delimitado, así como establecer su grado de dependencia de la autoridad civil en circunstancias excepcionales como ésas.

La dimensión humana, el auxilio y la superación de la emergencia inmediata, son la prioridad. Destaco esta dimensión pues, a nivel de expertos, la atención normalmente se vuelca hacia la revisión de las normas constructivas para hacerlas más seguras. Indudablemente, esta tarea es importante, pero no inmediata. Lo primero y esencial es elevar la capacidad institucional para encarar con máxima eficacia la catástrofe humana que se produce en las primeras horas.

Tercera: La emergencia inmediata, instante esencial de un desastre natural, exige fortalecer la capacidad de reacción de las empresas privadas que proveen los servicios públicos básicos. Estas empresas carecían de planes de contingencia, y -en muchos casos- procedieron con inusitada lentitud, al tiempo que la responsabilidad recaía en autoridades de gobierno con escasa capacidad de incidir en decisiones privadas. 
Cuarta: La organización institucional fue desbordada y la coordinación y mando se revelaron insuficientes para encarar un evento tan demoledor. La ONEMI (Oficina Nacional de Emergencia) estaba preparada para enfrentar eventos de magnitud media, como el sismo que golpeó el norte de Chile, con intensidad 8,0 y epicentro cercano a la pequeña ciudad de Tocopilla, en 2007, en una zona de escasa población; o desastres naturales como la erupción del volcán Chaitén, que en 2008 diezmó la ciudad del mismo nombre; o sequías e inundaciones como las sufridas en 2007 y 2008 en la zona central de Chile. Pero la ONEMI no estaba preparada, si es que alguna institución puede estarlo, para actuar con la amplitud y celeridad requeridas ante un sismo de tal magnitud.

Desde mi punto de vista, la ONEMI requerirá de una reorganización que contemple una línea de autoridad clara, mejor coordinación, y dotada de poder sobre las distintas instituciones llamadas a actuar en estas circunstancias, con máxima agilidad y mayores recursos.

Lo ocurrido pone en evidencia que es clave descentralizar una parte de la acción inmediata, reforzando así la capacidad de decisión local. Es imperioso, además, reforzar los sistemas regulatorios y órganos públicos, centrales y regionales, para supervisar los programas de contingencia de las empresas privadas proveedoras de servicios públicos.

Quinta: Es perentorio disponer de un plan de acción para proveer, en el menor tiempo posible, de vivienda temporal a las familias que quedan a la intemperie y a los comercios que ofrecen abastecimientos esenciales.

Para proteger a las familias que quedaron sin casa, en tres meses se instalaron 50 mil "mediaguas" de madera. Esto se logró en parte importante gracias a la fundación Un Techo para Chile vinculada a la Iglesia Católica, que produjo cerca del $40 \%$ de las viviendas requeridas. El resto fue fabricado por empresas privadas y su instalación contó con participación de los municipios y las Fuerzas Armadas.

Asimismo, el país debe contar con la capacidad de ejecutar un plan que contemple la reposición de capital e instalaciones de pequeñas empresas que proveen de servicios y empleo, como son las embarcaciones de pescadores artesanales en la costa, que resultaron destruidas por el maremoto. 
La experiencia de este terremoto también reveló una preparación insuficiente en salud. En ese sentido, el plan de acción debe incluir un programa para sustituir con prontitud hospitales caídos por hospitales de campaña, así como para contar con provisiones para adquirir hospitales modulares con rapidez. El costo de los hospitales modulares y sus plazos de instalación resultaron superiores a lo supuesto, debiendo desecharse la idea inicial anunciada por el nuevo gobierno.

Sexta: Falló el sistema de alarma de maremoto, a cargo del Sistema Hidrográfico y Oceanográfico de la Armada (SHOA). Los responsables no estaban en su sitio y tampoco evaluaron correctamente el riesgo. Aun cuando las olas gigantes se descargaron a los pocos minutos y las comunicaciones estaban dañadas, una alarma habría ayudado a advertir a quienes oían noticias en radios a pila o de automóviles, que todos los habitantes de las zonas costeras bajas afectadas por el maremoto debían desplazarse con rapidez a zonas altas.

Es imprescindible que el SHOA sea reorganizado, que disponga de recursos humanos renovados, equipamiento de calidad y de una coordinación eficiente y ágil con otros centros internacionales de alerta.

Igualmente, Chile debe elevar la calidad de su red sismográfica y estrechar la colaboración con países vecinos de la costa del Pacifico, como Perú, Colombia, México, y con países de Centro América, que han sufrido desastres sísmicos similares, para compartir con éstos experiencia e información. Siendo el país más expuesto del mundo a estas contingencias, Chile debe reforzar los equipos humanos y materiales. En ese sentido, la Universidad de Chile, encargada de las mediciones y líder en investigaciones geológicas en nuestro país, ha cumplido una labor fundamental, que es necesario preservar y fortalecer.

Séptima: Las fallas puntuales dejaron al descubierto la insuficiencia de los estudios de mecánica de suelos y de algunas normas antisísmicas. Por razones de costo, es frecuente que los estudios midan propiedades de los suelos en puntos distantes, bajo el supuesto de que los terrenos poseen características homogéneas en las zonas intermedias. Chile debe ampliar la cantidad y calidad de los estudios de mecánica de suelos. 
Igualmente, para el Ministerio de Obras Públicas resulta ineludible una revisión de las sorpresivas fallas acaecidas en la autopista concesionada de Vespucio Norte, en Santiago, al igual que en varios pasos sobre nivel y terraplenes en el nuevo Acceso Sur a Santiago, todas obras nuevas a cargo de empresas concesionarias extranjeras.

Asimismo, es del caso investigar las causas del colapso parcial del puente Juan Pablo II sobre el río Biobío, en Concepción, y definir los cambios necesarios en el diseño de puentes que se apoyan en lechos de resistencia variable, ya sea aumentando luces entre cepas, ensanchando apoyos en cabezales, y perfeccionando el comportamiento de amarres antisísmicos, con barras, corchetes u otras dispositivos de apoyo (ver Saragoni, 2010).

Las normas antisísmicas que regulan las instalaciones interiores de construcciones privadas y públicas revelaron graves falencias. Buen ejemplo de ello fue el aeropuerto de Santiago. La estructura del edificio soportó bien, pero en su interior cayeron techos, ductos, instalaciones eléctricas, iluminación, rociadores antiincendio. Si el terremoto hubiera golpeado a las 10 de la mañana, en vez de las 3, habríamos lamentado más víctimas. Por tanto, resulta fundamental perfeccionar las normas antisísmicas vigentes.

Octava: La supervisión del cumplimiento de las normas de diseño en la construcción de edificios es insuficiente. En la construcción inmobiliaria de altura, las normas relativas a materiales han sido modificadas en el Congreso Nacional. Las fallas detectadas obligan a indagar si las empresas privadas han cumplido con las normas constructivas vigentes, y si el sistema actual de autorizaciones de proyectos es riguroso, al igual que a adoptar nuevos procedimientos de certificación de cumplimiento.

Novena: Además del aprovisionamiento suficiente de elementos para confrontar la urgencia, en los días siguientes a un desastre natural es esencial disponer de equipamientos mayores. Destaco tres.

- Puentes mecano, para una instalación rápida que permita recuperar la conectividad terrestre con las localidades más dañadas. Así lo hicimos sobre el río Biobío. En diez días, el Ministerio de Obras Públicas instaló tres vías para 
empalmar con el puente Llacolén, el único que quedó en pie para atravesar de Norte a Sur, luego del colapso del puente Juan Pablo II.

- Un buen número de hospitales de campaña, que estén en manos del Ministerio de Salud, las Fuerzas Armadas, o de proveedores internacionales capaces de despacharlos de manera expedita. La solidaridad internacional permitió contar con varios de estos equipamientos.

- Plantas pequeñas para abastecer de agua. El maremoto dejó a muchas localidades costeras desabastecidas. A consecuencia de la ruptura de tuberías, la colmatación o destrucción de pozos, en la costa se requirió de plantas potabilizadoras y desalinizadoras.

Décima: Superada la emergencia, la etapa más compleja es la reconstrucción y reparación de lo dañado y, luego, el inicio de la construcción de lo nuevo.

La primera fase, de reconstrucción y reparación, suele demorar hasta 12 meses. En el caso chileno, seis meses después del terremoto, el nuevo gobierno informó de periodos de 18 meses para disponer de las construcciones modulares que sustituyan las 200 escuelas destruidas, y de a lo menos 24 meses para montar entre 8 y 10 hospitales modulares en la zona de catástrofe, plazos más prolongados que los indicados inicialmente (El Mercurio, 27 de agosto, p C7).

Esta fase supone recabar financiamiento adicional para esos primeros meses. Para este efecto, el presupuesto nacional debe ser modificado con reasignaciones, y se debe lograr financiamiento adicional vía créditos o modificaciones tributarias inmediatas.

Chile disponía de recursos en el Fondo de Estabilidad Económica y Social, aprobado por el Congreso en 2008, durante el Gobierno de la ex presidenta Michelle Bachelet. Este fondo, alimentado con los ingresos provenientes de los altos precios del cobre, hizo posible enfrentar la crisis financiera global de 2008-9, así como los primeros meses de la emergencia después del terremoto.

A futuro, es necesario incluir en el presupuesto nacional una provisión mayor contra desastres naturales. Considerando la tendencia actual del cambio climático que experimenta el planeta, es posible proyectar que catástrofes como ésta serán 
cada vez más frecuentes y onerosas, amenazarán más vidas debido al aumento de la población, a la elevada urbanización, a la existencia de viviendas instaladas en bordes de ríos o en laderas proclives a deslizamientos.

La forma de financiar el costo de un desastre de esta magnitud conlleva opciones políticas importantes desde el punto de vista fiscal y redistributivo. Si su financiamiento es con deuda, su pago se traslada a las nuevas generaciones; si es con impuestos, depende de quién tributa. Un impuesto general recaerá también sobre personas de menores ingresos; si es un aumento al impuesto a la renta de los ingresos altos o de las utilidades de empresas mayores, su impacto será más redistributivo.

Este segundo tema fue objeto de un debate principal entre el gobierno y la oposición en Chile, en cuanto al sujeto y a la duración del incremento tributario. La oposición insistió en un aumento permanente o más prolongado. Finalmente, se convino un alza temporal del impuesto a las utilidades de las "grandes" empresas y elevar el royalty (impuesto adicional a las utilidades operacionales) a las grandes corporaciones mineras.

Proteger a las familias más pobres que habitan áreas vulnerables también es una política de protección social y de combate a la pobreza. El Estado debe intervenir, erradicando a quienes viven en zonas de alto riesgo, adquiriendo para ellos terrenos seguros donde puedan instalarse a un costo que esté a su alcance, ya que normalmente éstos son más caros.

Undécima: La segunda fase, construcción de lo nuevo, exige preparar planes maestros que definan el tipo de ciudad o pueblo que la ciudadanía desea para el siglo 21. Sus habitantes desearán preservar cierta identidad histórica y trazar su futuro, cada uno puede tener diseños, materiales, tipos de construcción, edificios y espacios públicos diferentes, que servirán para orientar las inversiones y estimular la acción colectiva. (Ver las opiniones de arquitectos en El Mercurio, 25 de julio, Artes y Letras, pp. 2-3).

Dichos planes maestros deben encargarse, desde temprano, a equipos de expertos que hagan consultas con la ciudadanía y autoridad locales y regionales. Su trabajo debe correr paralelo y simultáneamente con los programas de emergencia y reconstrucción, de modo de poder empalmar a tiempo, cuando finalicen las fases 
más urgentes, y dar una perspectiva motivadora, antes que la inquietud o la sensación de abandono y frustración se propaguen entre la gente afectada. Se debe recoger el anhelo de los vecinos, lo que les dará una perspectiva esperanzadora.

El gobierno debe liderar el diseño y ejecución de esos planes maestros, con una perspectiva de varios años. De lo contrario, pueden acontecer dos riesgos: que las prioridades cambien y el impulso decaiga, o que se repose en demasía en la iniciativa privada, que si bien es eficaz para implementar programas específicos, no es apta para delegarle una tarea pública de largo plazo.

Semejante desafío, construir lo nuevo, puede abarcar entre uno y dos lustros. Su éxito dependerá de acuerdos amplios que trasciendan al gobierno en ejercicio, y de una participación ciudadana responsable, que aporte la creatividad y el compromiso de las organizaciones sociales, culturales y empresariales (ver Poduje, 2010).

Resulta urgente definir el criterio de demarcación de aquellas zonas donde se autorizará y aquéllas donde se prohibirá construir, por el peligro que representan para la vida de las personas. En terrenos costeros bajos es particularmente imperioso definir las zonas seguras y ofrecer terrenos alternativos. Es indispensable que el gobierno proceda a modificar la normativa existente sobre esta materia.

Duodécima: Se debe fortalecer y aumentar la educación de la población para enfrentar eventos de esta naturaleza.

Gracias al adiestramiento previo con educación y simulacros, muchas familias que habitan en las zonas costeras más afectadas por el maremoto reaccionaron adecuadamente y se alejaron con rapidez de la costa, evitando más muertes a consecuencia del maremoto.

Debido a la larga historia sísmica, los chilenos poseemos instinto y comportamientos ya internalizados. Sobre esa base, la educación debe fortalecerse, pues será una gran forma de prevención y defensa a futuro.

Cada escuela y municipio tiene que enfrentar a tiempo estas obligaciones, empleando todas las tecnologías de comunicaciones existentes. En cada escuela debe consagrarse un día por semestre o, a lo menos, al año para realizar ejercicios según el tipo de desastre natural más probable en la zona en que se encuentra. 
La educación es fundamental para reconocer los riesgos, protegerse, identificar rutas de escape y organizarse. No obstante, también es fundamental para preservar la salud mental de la población, previniendo y reduciendo las repercusiones sicológicas y siquiátricas de desastres naturales como el que azotó a nuestro país ese sábado 27 de febrero de 2010 a las 3:30 am.

\section{A MODO DE CIERRE}

Si ante pruebas tan duras, los chilenos corregimos a tiempo las falencias y actuamos con visión de futuro, podremos conseguir niveles más altos de seguridad. Se trata de una tarea colectiva, de largo plazo, que debe comprometer un esfuerzo sostenido y colectivo.

\section{REFERENCIAS BIBLIOGRÁFICAS}

Sarrazín, M. (2010). Revista Facultad de Ciencias Físicas y Matemáticas, № 48.

Poduje Iván (2010). “La voz de alerta tras el terremoto”. El Mercurio, 24 de julio, pp. 36-38.

El Mercurio, 25 de julio y 27 de agosto de 2010. 